\title{
Do neuroendocrine cells in human prostate cancer express androgen receptor?
}

\author{
J.L.M. Krijnen ${ }^{1}$, P.J.A. Janssen ${ }^{1}$, J.A. Ruizeveld de Winter ${ }^{1}$, H. van Krimpen ${ }^{1}$, F.H. Schröder ${ }^{2}$, T.H. van der Kwast ${ }^{1}$ \\ ${ }^{1}$ Department of Pathology, Erasmus University, Postbox 1738, NL-3000 DR Rotterdam, The Netherlands \\ ${ }^{2}$ Department of Urology, Erasmus University, Rotterdam, The Netherlands
}

Accepted: 25 August 1993

\begin{abstract}
The presence of androgen receptors (AR) in neuroendocrine cells was investigated in benign tissue of 10 prostatectomy specimens, in 12 prostatic adenocarcinomas with focal neuroendocrine differentiation and in 1 case of a pure neuroendocrine small cell carcinoma of the prostate. Neuroendocrine cells were defined by their reactivity with an antibody to chromogranin A. Monoclonal antibody F39.4 directed against the amino-terminal domain of the AR molecule was used to detect $A R$. $\mathrm{AR}$ and chromogranin A were simultaneously visualized with a double immunofluorescence technique. The results indicate that chromogranin positive cells in both benign and malignant prostatic tissue lack detectable expression of AR. No effect of endocrine therapy was noted. These results are in agreement with the hypothesis that prostatic neuroendocrine tumour cells represent an androgen insensitive cell population, which incidentally may expand to replace the androgen-sensitive tumour cell population during androgen ablation therapy.
\end{abstract}

\section{Introduction}

Most patients with metastasized prostate cancer benefit initially from androgen ablation therapy, but about $20 \%$ of cases are refractory to endocrine therapy (Lepor et al. 1982; Paulson 1983). The high response rate is in accordance with the observation that most human prostate cancers have a high content of androgen receptors (AR; Martelli et al. 1980; Concolino et al. 1982). Some recent immunohistochemical studies using antibodies to the amino-terminal domain of AR revealed that the proportion of AR positive tumour cells varied among prostate cancers; poorly differentiated prostate cancers tended to have a diminished proportion of AR positive tumour cells (Ruizeveld de Winter et al. 1990; Masai et al. 1990). In ligand binding studies on tumour cytosols, Gorelic et al. (1987) similarly noted heterogeneity of AR expression

Correspondence to: T.H. van der Kwast in prostate cancer. It can be envisaged that androgen withdrawal would lead to the selective expansion of the subset of AR negative tumour cells; however, in a previous paper we reported that the majority of hormone therapy-resistant prostate cancers consists largely of AR positive tumour cells (Van der Kwast et al. 1991). The mechanism underlying the transition to hormone independence still remains unclear.

Neuroendocrine cells producing a variety of peptide hormones are dispersed in the epithelial lining of prostatic ducts and glands. Peptide hormones are thought to play a regulatory role during the growth and differentiation of the prostate (reviewed by Di Sant'Agnese 1992). Similarly, neuroendocrine cells may be found in human prostate cancer, generally as a minor component, but occasionally constituting the entire neoplastic cell population. A few retrospective studies on prostate cancer have indicated that an increase in the proportion of tumour cells with neuroendocrine differentiation is negatively correlated with prognosis (Turbat-Herrera et al. 1988; Cohen et al. 1990). Abrahamsson et al. (1989) demonstrated an enrichment for tumour cells with neuroendocrine differentiation after oestrogen therapy of prostate cancer. Furthermore, some cases of prostate cancer with a minor neuroendocrine population showed a transition to a pure neuroendocrine malignancy after establishment of endocrine therapy (Stratton et al. 1986; Têtu et al. 1987). The latter observations suggest that prostatic tumour cells with neuroendocrine differentiation are not androgen sensitive and may be involved in the development of androgen unresponsiveness. The present study was undertaken to examine whether or not neuroendocrine cells in benign prostatic tissue and in prostate cancer are lacking in androgen receptors.

\section{Materials and methods}

Tissue specimens

Tissue specimens were obtained from patients with an established diagnosis of prostatic carcinoma and who underwent prostatec- 
Table 1. Presence of chromogranin A positive cells in prostatic carcinomas

\begin{tabular}{lllll}
\hline Surgery & Grading & $\begin{array}{l}\text { Endocrine } \\
\text { therapy }\end{array}$ & $\begin{array}{l}\text { Duration } \\
\text { (months) }\end{array}$ & $\begin{array}{l}\text { Number of } \\
\text { cells }^{\mathrm{c}}\end{array}$ \\
\hline TUR & $1(3)$ & None & & 4 \\
TUR & $1(3)$ & None & & 42 \\
Radical & $1(3)$ & None & 20 & 35 \\
TUR & $2(4)$ & CPA & & 36 \\
Radical & $2(4)$ & None & & 57 \\
TUR & $3(4)$ & None & 98 & 60 \\
TUR & $3(4)$ & CPA & & 46 \\
TUR & $3(5)$ & None & & 20 \\
TUR & $3(5)$ & None & 20 & 35 \\
TUR & $3(5)$ & Orchidect & 4 & 3 \\
TUR & $3(5)$ & Goserelin & 4 & 7 \\
TUR & $3(5)$ & Orchidect & 12 & 65 \\
TUR & $3(5)$ & Orchidect & 48 & \\
TUR & Small cell & None & & 4 \\
\hline
\end{tabular}

TUR, Transurethral resection; CPA, cyproterone acetate

a Surgery consisted of TUR or radical prostatectomy

b Prostatic carcinomas were scored according to the M.D. Anderson grading system; the Gleason growth pattern is given in parentheses

c The number of chromogranin A positive tumour cells examined for androgen receptor expression is given tomy $(n=10)$ or transurethral resection $(n=12)$. These cases had been selected from a larger series of prostatic carcinomas on the basis of the presence of neuroendocrine cells. The clinical data and the classification of the examined tumours according to the grading system of M.D. Anderson and the Gleason growth pattern (Ten Kate et al. 1986) are presented in Table 1. In six cases the tumour showed progressive growth despite androgen ablation therapy. The prostatic genesis of the smail cell (neuroendocrine) carcinoma was endorsed by the absence of a pulmonary tumour in the patient. Benign prostatic tissue was derived from parts of prostatectomy specimens that were not involved in the neoplastic process. Immediately after surgery the tissue samples were frozen in chilled isopentane and stored in liquid nitrogen until use.

\section{Immunohistochemistry and immunofluorescence}

Immunohistochemistry and immunofluorescence were performed on cryostat sections of $4 \mu \mathrm{m}$ in thickness. Expression of chromogra$\operatorname{nin}$ A was visualized with a monoclonal antibody obtained commercially from Organon Technika, The Netherlands; the antibody was diluted 1:80 in phosphate-buffered saline (PBS) before using in the assay. Binding of the anti-chromogranin antibody was visualized by the indirect conjugated peroxidase method. Frozen sections were fixed for $10 \mathrm{~min}$ in $4 \%$ formalin in PBS prior to incubation with anti-chromogranin, as this fixation enhances the sensitivity of detection in comparison to acetone-fixed frozen sections. For detection of AR, monoclonal antibody F39.4 raised against amino acids 300-320 of the human AR molecule was applied (Zegers et al. 1991).

Preliminary experiments indicated that a sequential double immunoenzymatic method for simultaneous detection of AR and chromogranin did not yield satisfactory results: the immunoperoxidase staining for $\mathrm{AR}$ interfered with the subsequent demonstration of chromogranin. Therefore a double-immunofluorescence method was developed for use on cryostat sections, according to the following procedure. The sections were fixed in $4 \%$ formalin in PBS, rinsed in PBS for $5 \mathrm{~min}$, and dehydrated in chilled $\left(-20^{\circ} \mathrm{C}\right)$ methanol for $4 \mathrm{~min}$ and chilled acetone for $2 \mathrm{~min}$. The slides were subsequently rinsed in PBS and preincubated with nonimmune goat serum (DAKO, Glostrup, Denmark) for $15 \mathrm{~min}$. After an overnight incubation with F39.4 diluted 1:4000, the slides were incubated sequentially for 30 min each with biotinylated goat anti-mouse immunoglobulin ( $\mathrm{Ig}$; DAKO) diluted 1:400 in PBS, avidin-conjugated fluorescein isothiocyanate (FITC) diluted 1:200 in PBS, biotinylated goat anti-avidin diluted $1: 200$, and again with avidin-FITC. Between incubations the slides were rinsed in PBS.

To demonstrate chromogranin A by double immunofluorescence, the slides were subsequently exposed to anti-chromogranin A (diluted 1:80), alkaline phosphatase labelled rabbit anti-mouse Ig and the substrate naphthol ASB and Fast Red obtained from the Vector substrate kit (Vector, Burlingame, Calif., USA). The substrate was dissolved in 4\% polyvinyl alcohol mol. wt. 49000 (Fluka, Neu-Ulm, Germany) in order to reduce the diffusion of the precipitate. After rinsing in distilled water the slides were covered with Vectashield (Vector) and a coverslip. Evaluation was performed with a Zeiss light mictoscope equipped with an excitation filter of 450-500 nm and an LP515 long-pass filter. A KP560 interference red-free filter was used to detect $A R$ selectively.

Control slides were incubated with all the reagents mentioned above, but either F39.4 or anti-chromogranin A or both antibodies were replaced by PBS. No non-specific background fluorescence for nuclei and cytoplasm respectively or both was noted in these slides. As a control for the feasibility of using double immunofluorescence to detect a cytoplasmic marker and nuclear AR within the same cell, the anti-chromogranin antibody was replaced by mouse monoclonal antibody ER-PR1, specific for prostate specific antigen (PSA; Gallee et al. 1986). The double-immunofluorescence technique clearly demonstrated the simultaneous expression of nuclear AR and cytoplasmic PSA in the secretory epithelial cells lining prostatic glands (Fig. 1).

\section{Results}

\section{Benign prostatic tissue}

Neuroendocrine cells demonstrated by their reactivity with anti-chromogranin A antibody were observed predominantly along prostatic ducts, but also in the lining of prostatic glands. Most frequently they occurred as single cells, but occasionally in small clusters. The 
neuroendocrine cells were located in a basal position. In double-immunofluorescence staining, the nuclei of the luminal, but not basal epithelial cells, were distinctly labelled. In none of a total of 100 chromogranin-positive cells examined in the benign prostatic glands of 10 different prostatectomy specimens was AR expression detectable (Figs. 2 and 3 ).

\section{Prostatic cancer}

Immunohistochemistry for chromogranin was performed on a series of 12 transurethrally resected tissue specimens and on two prostatectomy derived tissue samples. Thirteen prostatic carcinomas contained variable numbers of tumour cells with neuroendocrine differentiation. In some tumours the neuroendocrine cells were present in small foci. Double-immunofluorescence studies of these tissue samples failed to demonstrate the presence of AR in chromogranin A-positive cells (Figs. 4 and 5), although the nuclei of the surrounding chromogranin A-negative cells were intensely labelled for AR. No effect of endocrine therapy was observed on the expression of AR in neuroendocrine and non-neuroendocrine cells (Table 1). One transurethrally resected specimen contained a small cell carcinoma, which was largely composed of chromogranin-positive tumour cells. With F39.4 antibody only sporadic faintly AR positive tumour cells were seen in this tumour (Fig. 6).

\section{Discussion}

This study has demonstrated that prostatic neuroendocrine cells lack a detectable expression of AR. This observation holds true for neuroendocrine cells lining benign prostatic glands and ducts, and also for those which are an intrinsic component of prostatic adenocarcinomas. The differentiation grade of the prostatic carcinoma did not affect the outcome of the results (Table 1). In addition, we showed that the pure neuroendocrine small cell prostatic carcinoma lacked detectable $\mathrm{AR}$. The latter is in accordance with the reported absence of $A R$ in a xenografted small cell neuroendocrine carcinoma line originating from a human prostatic carcinoma (Van Haaften-Day et al. 1987).

The more aggressive biological behaviour of prostatic carcinomas with a neuroendocrine component has been attributed to a lack of responsiveness of the neuroendocrine cells to androgen ablation therapy (Di Sant'Agnese 1992). This results in an enrichment for the neuroendocrine tumour component. The AR negative, androgen insensitive neuroendocrine tumour cells, if endowed with the capacity to proliferate, could eventually give rise to the development of a pure neuroendocrine carcinoma (Stratton et al. 1986; Têtu et al. 1987). The lack of detectable AR observed in neuroendocrine prostatic (tumour) cells is in complete agreement with the above hypothesis. However in a recent study, Nakada et al. (1993) failed to demonstrate a difference in AR ex- pression between non-neuroendocrine and neuroendocrine cells in benign and malignant prostatic tissues. These authors used antibody ANI-15 for detection of AR. The reactivity of this antibody with the nuclei of basal cells lining the prostatic glands, as reported by Masai et al. (1990), contrasts with the reactivity pattern of antibody F39.4 (Ruizeveld de Winter et al. 1991). In addition, differences in tissue processing and in the double-immunostaining technique may help to explain the discrepancy of the findings reported by these authors.

It should be noted that the (therapy-induced) transition of a prostatic adenocarcinoma into a frankly neuroendocrine carcinoma is a very infrequent phenomenon. Moreover, about $80 \%$ of endocrine therapy-resistant progressive prostatic carcinomas contain a high proportion of AR positive tumour cells (Van der Kwast et al. 1991). This implies that the presence of AR within prostatic carcinoma cells does not necessarily indicate their androgen dependence.

Dispersed neuroendocrine tumour cells might influence the proliferation of surrounding non-neuroendocrine prostatic tumour cells by paracrine stimulation. A variety of peptide hormones have been demonstrated in prostatic neuroendocrine cells by immunohistochemistry. Several of these peptides are known to have growth factor-like activity and may play a paracrine role in the development of hormone independence of AR positive prostatic adenocarcinoma cells (Di Sant'Agnese 1992). In this paper we have shown that in prostatic adenocarcinomas with focal neuroendocrine differentiation, most of the surrounding non-neuroendocrine tumour cells display nuclear AR expression, independently of the previous therapeutic regimen. Power et al. (1991) demonstrated that a catecholamine neurotransmitter could induce ligand-independent activation of some steroid receptors (progesterone receptor and oestrogen receptor) via a cell membrane associated dopamine receptor. If a similar ligand independent activation mechanism also applies to $\mathrm{AR}$, biogenic amines derived from neuroendocrine cells could similarly play a major role in the process of androgen independent activation of (AR positive) tumour cells.

Although the secretory epithelial cells of prostatic glands are AR positive, the basal cells generally resemble neuroendocrine cells in that they lack a detectable AR (Ruizeveld de Winter et al. 1991). This common feature suggests a close relationship between the two cell types. Some authors have speculated on the multidirectional differentiation of a prostatic stem cell into either secretory epithelial cells or neuroendocrine cells (Schron et al. 1984; DeLellis et al. 1984; Roy et al. 1987). Further experimental studies should be designed with the aim of identifying and characterizing the factors involved in the induction of neuroendocrine differentiation in prostatic epithelium.

Acknowledgements. The authors thank Prof. Dr. F.T. Bosman for helpful advice and Mr. F. van der Panne for excellent photography. 

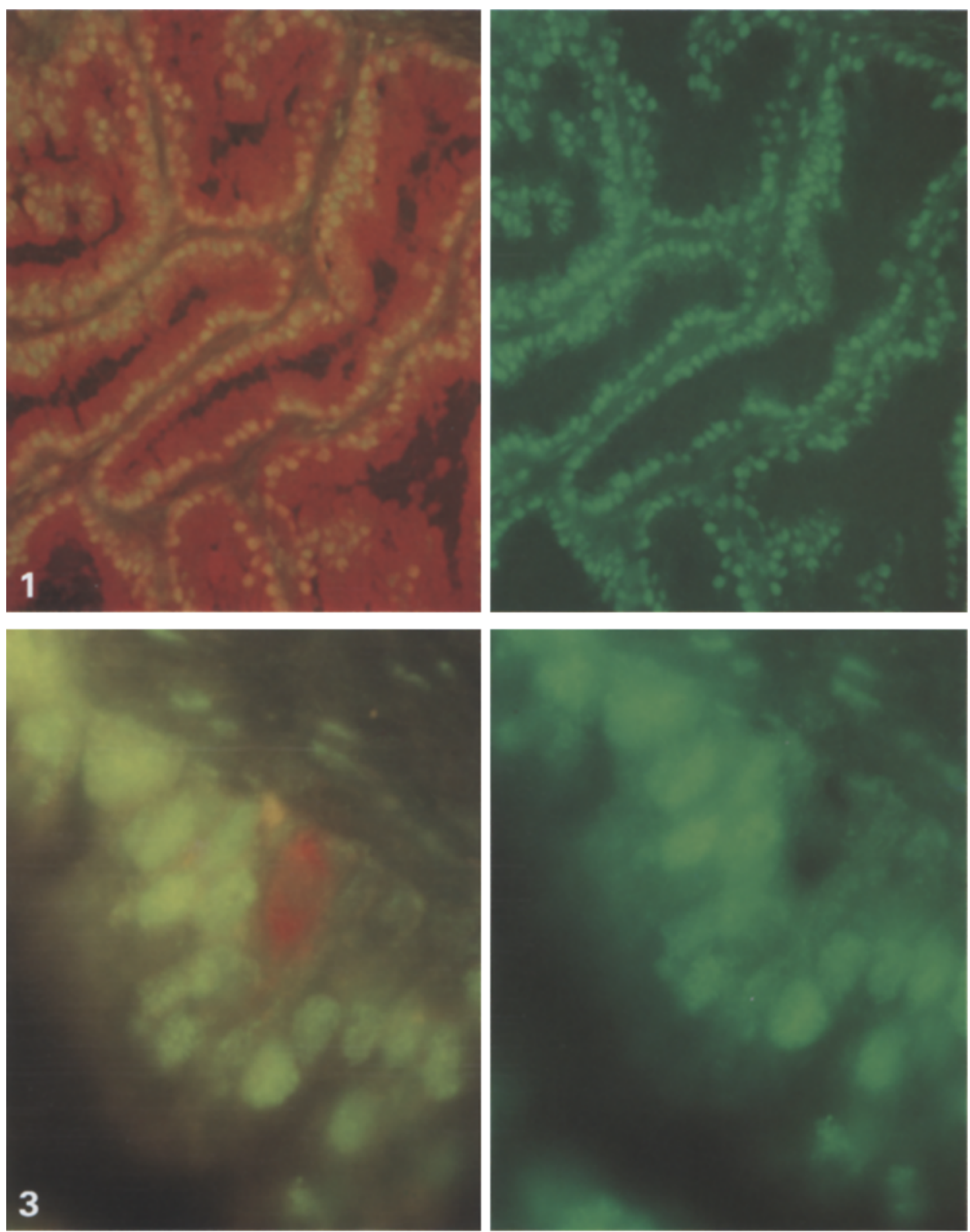

Fig. 1. Photomicrograph of benign prostatic gland demonstrating androgen receptor (AR; green) and prostate specific antigen (PSA; red) in secretory epithelial cells. Left panel, Simultaneous demonstration of AR and PSA; right panel, intense nuclear fluorescence for $A R$ $(\times 40)$

Fig. 3. Higher magnification of neuroendocrine cell surrounded by secretory epithelial cells in benign gland. Left panel, Simultaneous demonstration of AR and chromogranin A; right panel, intense nuclear fluorescence for AR. Note that the neuroendocrine cell does not display nuclear fluorescence for $\mathrm{AR}(\times 250)$

Fig. 5. Photomicrograph of glandular formations in a moderately differentiated adenocarcinoma with some neuroendocrine tumour cells. Left panel, Simultaneous demonstration of AR and chromogranin $\mathrm{A}$; chromogranin positive cells are surrounded by AR positive tumour cells. Right panel, intense nuclear fluorescence for AR. Note that the neuroendocrine cells do not display nuclear fluorescence for AR $(\times 100)$ 

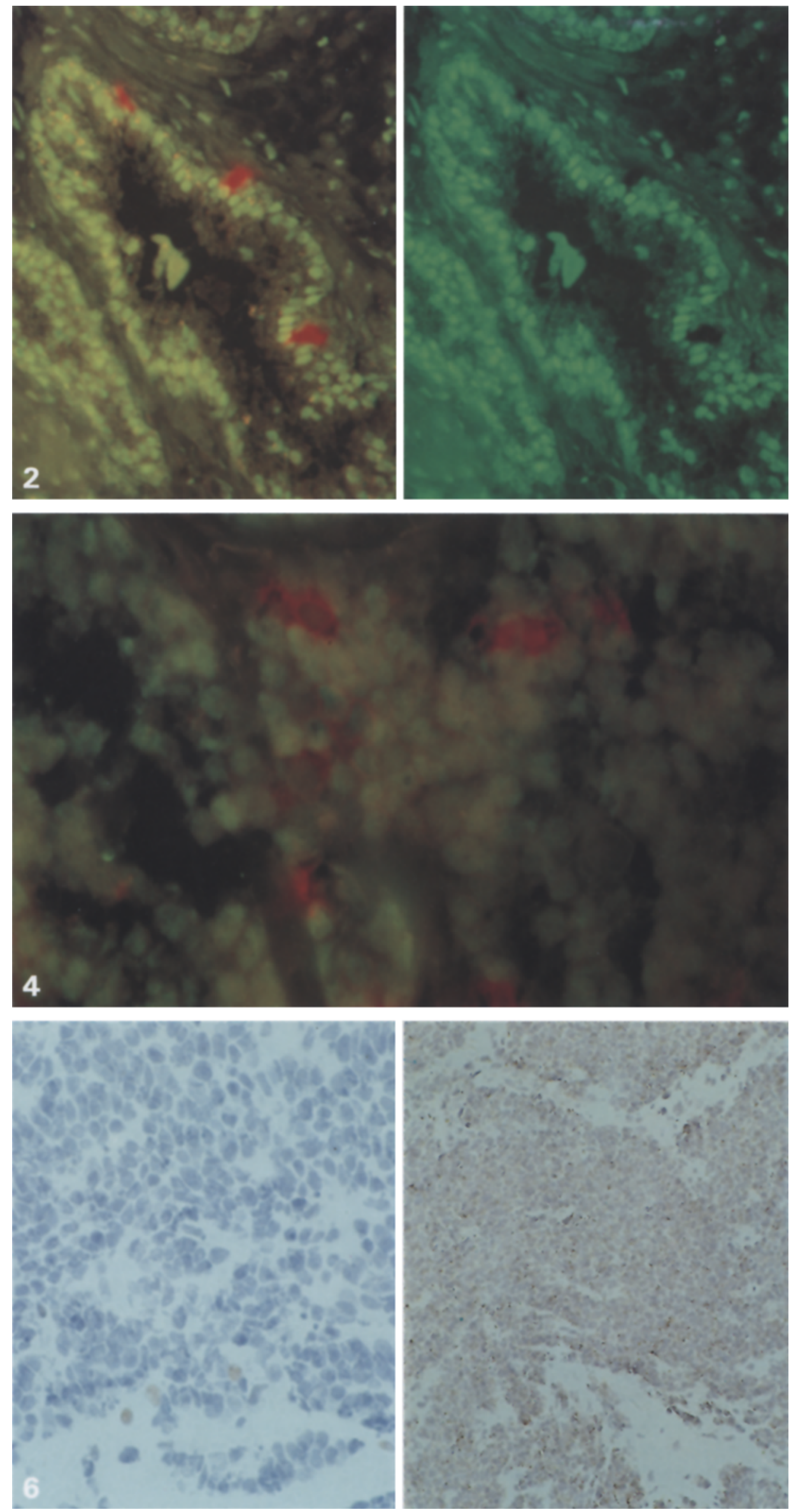

Fig. 2. Low power photomicrograph of benign prostatic gland demonstrating $\mathrm{AR}$ (green) and chromogranin A (red). Left panel, Simultaneous demonstration of AR and chromogranin $\mathrm{A}$; right panel, intense nuclear fluorescence for AR Note that the neuroendocrine cells do not display AR $(\times 40)$

Fig. 4. Focal area with neuroendocrine differentiation in poorly differentiated adenocarcinoma. AR negative neuroendocrine cells are surrounded by AR positive non-neuroendocrine tumour cells $(\times 100)$

Fig. 6. Immunostaining of a prostatic small cell carcinoma with anti$\mathrm{AR}$ antibody (left) and antichromogranin A (right). The tumour is largely AR negative, while AR positive tumour cells are rarely encountered (left). Most tumour cells express chromogranin A (right) $(\times 100)$ 


\section{References}

Abrahamsson PA, Falkmer S, Fält K, Grimelius L (1989) The course of neuroendocrine differentiation in prostatic carcinomas. Pathol Res Pract 185:373-380

Cohen RJ, Glezerson G, Haffejee Z, Afrika D (1990) Prostatic carcinoma: Histological and immunological factors affecting prognosis. Br J Urol 66:405-410

Concolino G, Marocchi A, Margiotta G, Conti C, Di Silverio F, Tenaglia R, Ferraro F, Bracci U (1982) Steroid receptors and hormone responsiveness of human prostatic carcinoma. Prostate $3: 475-482$

DeLellis RA, Tischler AS, Wolfe HJ (1984) Multidirectional differentiation in neuroendocrine neoplasms. J Histochem Cytochem 32: 899-904

Di Sant'Agnese PA (1992) Neuroendocrine differentiation in human prostatic carcinoma. Hum Pathol 23:287-296

Gallee MPW, Van Vroonhoven CCJ, Van der Korput JAGM, Van der Kwast TH, Ten Kate FJW, Romijn JC, Trapman J (1986) Characterization of monoclonal antibodies raised against the prostatic cancer cell line PC-82. Prostate 9:33-45

Gorelic LS, Lamm DL, Ramzy I, Radwin HM, Shain SA (1987) Androgen receptors in biopsy specimens of prostate adenocarcinoma. Heterogeneity of distribution and relation to prognostic significance of receptor measurements for survival of advanced cancer patients. Cancer 60:211-219

Lepor H, Ross A, Walsh PC (1982) The influence of hormonal therapy on survival of men with advanced prostatic cancer. J Urol 128:335-340

Martelli A, Soli M, Berovich E, Prodi G, Grilli S, De Giovanni C, Galli MC (1980) Correlation between clinical response to endocrine therapy and occurrence of receptors in human prostatic cancer. Urology 16:245-249

Masai M, Sumiya H, Akimoto S, Yatani R, Chang C, Liao S, Shimazaki J (1990) Immunohistochemical study of androgen receptor in benign hyperplastic and cancerous human prostates. Prostate 17:293-300

Nakada SY, Di Sant'Agnese PA, Moynes RA, Hiipakka RA, Liao S, Cockett ATK, Abrahamsson P-A (1993) The androgen receptor status of neuroendocrine cells in human benign and malignant prostatic tissue. Cancer Res 53:1967-1970

Paulson DF (1983) Lesson 17: prognostic factors in androgen independent prostatic carcinoma. American Urological Association Update Ser 2:1-8

Power RF, Mani SK, Codina J, Conneely OM, O'Malley BW (1991) Dopaminergic and ligand-independent activation of steroid hormone receptors. Science 254:1636-1639
Roy JY, Têtu B, Ayala AG, Ordonez NG (1987) Small cell carcinoma of the prostate. II. Immunohistochemical and electron microscopic studies of 18 cases. Cancer 59:977-982

Ruizeveld de Winter JA, Trapman J, Brinkmann AO, Boersma WJA, Mulder E, Schröder FH, Claassen E, Van der Kwast ThH (1990) Androgen receptor heterogeneity in human prostatic carcinomas visualized by immunohistochemistry. J Pathol $161: 329-332$

Ruizeveld de Winter JA, Trapman J, Vermey M, Mulder E, Zegers ND, Van der Kwast TH (1991) Androgen receptor expression in human tissues: An immunohistochemical study. J Histochem Cytochem 39:927-936

Schron DS, Gipson T, Mendelsohn G (1984) The histogenesis of small cell carcinoma of the prostate: an immunohistochemical study. Cancer 53:2478-2480

Stratton M, Evans DJ, Lampert JA (1986) Prostatic adenocarcinoma evolving into carcinoid: selective effect of hormonal treatment. J Clin Pathol 39:750-756

Ten Kate FJW, Gallee MPW, Schmitz PIM, Jöbsis AC, Van der Heul RO, Prins MEF, Blom JHM (1986) Controversy in grading of prostatic carcinoma: interobserver reproducibility of five different grading systems. World J Urol 4:147-152

Têtu B, Ro JY, Ayala AG, Johnson DE, Logothetis C, Ordonez NG (1987) Small cell carcinoma of the prostate. I. A clinicopathologic study of 20 cases. Cancer 59:1803-1809

Turbat-Herrera EA, Herrera GA, Gore I, Lott RL, Grizzle WE, Bonnin JM (1988) Neuroendocrine differentiation in prostatic carcinomas: a retrospective autopsy study. Arch Pathol Lab Med 112:1100-1105

Van Haaften-Day C, Raghavan D, Russell P, Wills EJ, Gregory P, Tilley W, Horsfall DJ (1987) Xenografted small cell undifferentiated cancer of the prostate: possible common origin with prostatic adenocarcinoma. Prostate $11: 271-279$

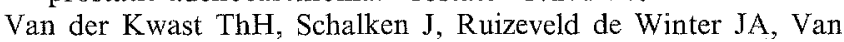
Vroonhoven CCJ, Mulder E, Boersma W, Trapman J (1991) Androgen receptors in endocrine-therapy-resistant human prostate cancer. Int J Cancer 48:189-193

Zegers ND, Claassen E, Neelen C, Mulder E, Van Laar JH, Voorhorst MM, Berrevoets CA, Brinkmann AO, Van der Kwast ThH, Ruizeveld de Winter JA, Trapman J, Boersma WJA (1991) Epitope prediction and confirmation for the human androgen receptor: generation of monoclonal antibodies for multiassay performance following the synthetic peptide strategy. Biochim Biophys Acta 1073:23-32 